\title{
Resource-harvester cycles caused by delayed knowledge of the harvested population state can be dampened by harvester forecasting
}

\author{
Matthew W. Adamson ${ }^{1}$ (D) $\cdot$ Frank M. Hilker ${ }^{1}$ \\ Received: 27 September 2019 / Accepted: 29 April 2020 / Published online: 16 May 2020 \\ (C) The Author(s) 2020
}

\begin{abstract}
The monitoring of ecosystems and the spread of information concerning their state among human stakeholders is often a lengthy process. The importance of mutual feedbacks between socioeconomic and ecological dynamics is being increasingly recognised in recent studies, but it is generally assumed that the feedback from the environment is instantaneous, ignoring any delay in the spread of ecosystem knowledge and the resulting potential for system stability loss. On the other hand, human actors rarely make purely myopic socioeconomic decisions as is often assumed. Rather, they show a degree of foresight for future utility which may have an opposing, stabilising effect to any delay in knowledge. In this paper, we consider a generic resource-harvester model with delayed ecosystem knowledge and predictive behaviour by the harvesters. We show that delays in the spread of information about the resource level can destabilise the bioeconomic equilibrium in the system and induce harvesting cycles or the collapse of the resource. Sufficiently farsighted prediction by the harvesters can stabilise the system, provided the delay is not too long. However, if the time horizon of prediction is too long relative to the timescale of resource growth, prediction can be destabilising even in the absence of delay. The results imply that effective monitoring of ecosystems and fast dissemination of the results are necessary for their sustainable use and that efforts to promote appropriate foresight among ecosystem users on the personal and institutional level would be beneficial to the stability of coupled socioeconomic-ecological systems.
\end{abstract}

Keywords Social-ecological system $\cdot$ Time horizon $\cdot$ Time delay $\cdot$ Sustainable harvesting $\cdot$ Common pool resource $\cdot$ Knowledge transfer

\section{Introduction}

Maintaining harvests of wildlife populations at a sustainable level is one of the major challenges facing ecologists today, particularly populations which serve as open access resources, the harvesting of which cannot be controlled for sociological

Electronic supplementary material The online version of this article (https://doi.org/10.1007/s12080-020-00462-x) contains supplementary material, which is available to authorized users.

Matthew W. Adamson

matthew.adamson@uni-osnabrueck.de

Frank M. Hilker

frank.hilker@uni-osnabrueck.de

1 Institute of Environmental Systems Research and Institute of Mathematics, University of Osnabrück, Barbarastraße 12, 49076 Osnabrück, Germany or political reasons (Clark 2010). In this case, most of the costs of harvesting a population to low levels or even extinction are externalised to society as a whole, so that the decision to harvest or not and on how much harvesting effort to make is dominated by the short-term profitability of the action, rather than by questions of long-term sustainability (Hardin 1968; Ostrom 1990). For this reason, the harvesting of such populations can lead to resource-harvester cycles due to the interplay of the nonlinear dynamics of the harvested population and a harvesting effort which varies according to the profitability of the resource (Bjørndal and Conrad 1987; Fryxell et al. 2010). Although there is research arguing that natural population cycles can be beneficial for ecosystem resilience and the maintenance of biodiversity in some cases (Barraquand et al. 2017), undamped cycles can be detrimental to the resilience of a population because they can cause it to drop to low densities at which it is at risk of collapse due to noise, external shocks, or interactions with mechanisms of critical depensation such as Allee effects, and are therefore a problem 
for the long-term sustainability of harvesting (Lande et al. 2003; Worm et al. 2009; Pinsky et al. 2011). Severe cycles can also lead to socioeconomic problems such as a local loss of stable employment, severed links between harvesters and the local environment as local harvesters are disproportionately hit during periods of economic collapse, and price fluctuations in related economic sectors (Steele et al. 1992; Cashin et al. 2015).

Maintaining the sustainable use of biological resources is challenging because of several recognised features unique to such resources. Firstly, there are multiple forms of uncertainty inherent in ecosystems: there is variability in stock recruitment due to ecological or environmental fluctuations (Shelton and Mangel 2011), surprising responses to harvesting can take place due to ecosystem effects or the existence of unseen tipping points (King et al. 2015), and the size of the stock can itself be uncertain, leading to overharvesting of the resource (Gustafsson et al. 1999). On the socioeconomic side, many of the drawbacks of unsustainable resource use are externalised to communities, rather than affecting harvesters directly, which leads to difficulties in obtaining cooperation among groups of harvesters (Ostrom 1990; Clark 2010). This can be further aggravated by discrepancies between political borders and resource boundaries. Another complication is the mismatch between the short-termism of economic decisionmaking and the often far longer time scale of ecological growth and recovery (Clark 2010). Finally, most harvesting of biological resources entails collateral damage to ecosystems, such as bycatch in fisheries (Lewison et al. 2004), so that governance of biological resources can rarely be considered in isolation from the surrounding ecosystem.

Since many mechanisms in social-ecological systems, such as resource cycles, are driven by the feedback between the social and ecological factors, modelling social and ecological systems separately is generally insufficient to inform sustainable governance of biological resources (Berkes et al. 2002). Instead, socioeconomic-ecological models need to be considered, in which human social factors and/or economic behaviour are treated as dynamic variables alongside ecosystem components. Examples of such socioeconomic variables include the intensity of exploitation of a resource (Smith 1969; Bjørndal and Conrad 1987; Fryxell et al. 2010; Bieg et al. 2017), the level of cooperativeness in terms of sustainable resource harvesting (Tavoni et al. 2012), and a reduction of pollutant emissions (Suzuki and Iwasa 2009; Beckage et al. 2018). Human behaviour is complex, and representing its response to changes in the ecosystem state in such models is understandably a contentious issue with many different approaches being taken. The most popular of these in the literature are those based on mass-action principles (Smith 1969; Bjørndal and Conrad 1987; Fryxell et al. 2010), the replicator equation (Taylor and Jonker 1978; Hofbauer and Sigmund 1998), and stochastic best-response dynamics (Foster and
Young 1990; Hofbauer and Sigmund 1998). However, the vast majority of coupled socioeconomic-ecological models using each of these particular frameworks make one assumption which is rarely mentioned: that socioeconomic decisions are taken based purely on the present resource level or ecosystem state.

A little reflection shows that the assumption of instantaneous feedback from the ecosystem to the human socioeconomic behaviour is untenable. Firstly, it implies that human agents in the system have instantaneous knowledge of the exact state of the ecosystem at no cost. In terms of resource governance, observation of the ecosystem not only has a cost, but knowledge of the system is imperfect and both the acquisition of this information and its circulation among resource users takes time, especially in the case of information concerning mobile biological resources (Ostrom 1990, 2009). There should then be a time delay or lag in the feedback from the environment to socioeconomic decisionmaking, in the sense that the present decisions depend explicitly on a past ecosystem state, rather than its current state (Berryman 1991; Berryman and Turchin 2001). For instance, in the management of fisheries, Holland (2010) reports that 'there is typically at least a two year lag between the data used for the assessment and the implementation of the management recommendation based on it.' Generally, however, explicit time delays in socioeconomic-ecological systems are only considered in ecological processes (Brauer 1979; Biggs et al. 2009; Xia et al. 2009; Hastings 2016), with a few exceptions (Botsford et al. 1983).

Systems with time delays are widely studied, and sufficiently large delays are well known to destabilise equilibrium dynamics in a wide range of fields such as ecology (Hutchinson 1948; May 1973; Jankovic and Petrovskii 2014) and engineering (Maxwell 1868), as well as biology, chemistry, economics, mechanics, viscoelasticity, physics, and physiology (Niculescu 2001; Richard 2003). The case of a resource-harvester system with a delayed response in the harvesting effort is directly analogous to that of a predator-prey system with a maturation delay in the predator. Without a time delay, the cycles that can be present in predator-prey systems and resource-harvester systems often show a phase difference in the oscillations of the two components: the predator/harvest dynamics respond slowly to changes in those of the prey/resource and consequently lag behind. A similar slow response can be seen in a resource-harvester system when the price of the resource increases slowly in response to its scarcity, leading to multistability and the appearance of tipping points (Fryxell et al. 2017). Such lags in the dynamics of one of the system components are distinct from an explicit time delay, since the predator/harvester dynamics still depend on the current prey/resource level, even if their response is slow enough that the coexistence equilibrium is overshot. Phase-shifted oscillations, however, can be 
induced or worsened in predator-prey systems through the inclusion of an explicit delay in maturation (Gourley 1996). Sufficiently large time delays in socioeconomic responses to an ecosystem state can therefore be expected to work against sustainable harvesting by either causing or worsening resource-harvester cycles. This has been confirmed in a few model studies, both for resource-harvester effort dynamics (Botsford et al. 1983) and for fisheries management policy (Kell et al. 2005).

Moreover, when the feedback from the ecosystem to human decision-making is only given in terms of the present state of the ecosystem, human agents are also considered to have absolutely no regard for future states of the ecosystem. Ironically, while the human agents have perfect knowledge of the ecosystem as it is today, they are assumed to have no idea what state it was in yesterday and not to care in what state it will be in tomorrow. In reality, resource harvesters or regulators remember previous resource levels and can use this memory to anticipate future levels. In fisheries management, forecasting is central (Haltuch et al. 2019) as a way to anticipate fish stocks or to estimate current stocks from outdated data. In European fisheries, for instance, regulators determine total allowable catch rates for the next year based on a 2-year catch forecast, made using data from the previous year (De Oliveira et al. 2009). Forecasting on the part of resource harvesters, though in comparison to that of regulators it may be more rudimentary and unconsciously made, should also exert an influence on their socioeconomic decisions.

Systems involving the prediction of future environmental system states are rarely studied. One classical exception is the consideration of 'rational expectations' in resource economics (Berck and Perloff 1984; Clark et al. 2005), based on the completely opposite assumption to myopic decision-making: harvesters are considered to have perfect knowledge of the resource stock for all future time. However, outside of stationary bioeconomic equilibria, such an assumption is clearly not viable. The more realistic situation is that future environmental states are predicted, but inexactly and only for a limited time in the future. This is a contrary process to a time delay in the feedback, in the sense that dynamics depend upon an anticipated future state as opposed to an actual past state. Therefore, a clear hypothesis to make is that prediction on the part of harvesters should have a stabilising effect on resource-harvester cycles. A recent paper from Bury et al. (2019) seems to support this hypothesis: a socio-climate model was considered in which the human behaviour was based upon a linear extrapolation of climate trends up until a future time horizon, and it was found that longer time horizons resulted in a smaller rise in temperature before global warming was reversed. Henderson et al. (2016) have also reported a stabilising effect of greater foresight in a socioecological model, represented by lower discounting of the utility based on the present environmental state.
A stabilising effect of human foresight, however, is not self-evident, and further model studies investigating the consequences of foresight on the stability of social-ecological systems are still needed, particularly in simpler, more tractable models where prediction can be investigated directly. Especially in the presence of delay, the stabilising effect of foresight comes into question: in this case, the effect of inherent time delays in the human knowledge of the resource level or ecosystem state may conflict with any beneficial effect of predicting future states. In supply chain management, for example, the interaction between time lags and forecasting of demand along supply chains can cause pronounced fluctuations through the 'bullwhip effect' (Barlas and Gunduz 2011). A similar result is seen in the fisheries management model of Kell et al. (2005), in which management recommendations were based on two-season forecasts from one-season-old data. Even with forecasting, large amplitude oscillations in yield and effort were seen to arise from the management procedure itself due to the delay in the data.

Two important open questions are therefore whether and to what extent can human forecasting reliably stabilise socialecological systems, and if so, what is the outcome of the conflict between such forecasting and the destabilising effect of delays in the acquisition and application of information on the ecosystem information? In this paper, we address these issues by considering a discrete-time resource-harvester model in which delayed knowledge transfer and simple resource forecasting are incorporated into the harvest effort dynamics.

\section{Model description}

As a starting point, let us consider a discrete-time system of two equations describing the harvest of an open-access resource:

$$
\begin{aligned}
X_{t+1} & =X_{t} e^{r\left(1-\frac{X_{t}}{K}\right)-q E_{t}}, \\
E_{t+1} & =E_{t} e^{\eta\left(p q X_{t}-c\right)} .
\end{aligned}
$$

Here, $X_{t}$ is the resource density, and $E_{t}$ the harvesting effort at time $t$. The renewal of the population follows the Ricker equation (Ricker 1954), with basic growth parameter $r>0$ and carrying capacity $K>0$. The rate at which the population is harvested is determined by multiplying the harvesting effort $E_{t}$ by the catchability coefficient $q>0$.

The change in the harvesting effort in the system is determined by the sign of the per-season profit per unit effort, $\pi_{t}=$ $p q X_{t}-c$, where $p>0$ is the per unit price of the resource, and $c$ is the cost per unit effort. $\eta>0$ is a stiffness parameter, which determines the difference in time scale between the resource and harvest effort dynamics. The system can be thought of as a version of the model of Fryxell et al. (2010) in the absence of harvest quotas and negative feedback in the harvesting effort, 
or alternatively as a discretisation of a continuous-time system consisting of a resource growing according to the logistic equation, with mass-action harvesting at a harvesting effort changing at a rate proportional to the profitability of harvesting (Smith 1969).

This system has a single nontrivial equilibrium at the zeroprofit condition, $p q X_{t}-c=0$, which can be stable in some cases, but undamped oscillations around this equilibrium are also possible when, e.g. the cost per unit effort $c$ is low, due to the feedback between the socioeconomic behaviour and the ecological dynamics. The mechanism of such cycles is essentially the same as for predator-prey cycles: when the resource population level is low, harvesting is uneconomical and the harvesting effort drops to low values such that the population can recover. However, the harvesting effort stays low for long enough that the resource level can rise and overshoot the zero-profit equilibrium, so that harvesting becomes highly profitable and harvesting effort booms, driving the population to low densities again.

As a simple representation of a delay in the acquisition of information about the resource level, we consider that the harvesters only know and make decisions based on a single outdated resource level $X_{t-\tau}$ :

$E_{t+1}=E_{t} e^{\eta\left(p q X_{t-\tau}-c\right)}$,

where $\tau$ is the number of seasons which it takes for knowledge of the resource to be acquired and to reach the harvesters. In general, it is also possible to consider models in which the resource levels in intervening seasons, $X_{\tau-1}, \ldots, X_{t}$, also influence the harvesters' socioeconomic decisions according to a weighting determined by how available and up-to-date the information is about the resource in the given season.

To incorporate foresight on the part of the harvesters, we allow a consideration of future resource levels to influence their behaviour. A simple way to represent this is to consider that the harvesters linearly extrapolate the trend of the two most recent known resource levels and base their harvesting decision on a predicted resource level $\widehat{X_{t}}=X_{t-\tau}+s\left(X_{t-\tau}-X_{t-\tau-1}\right)$, as in Bury et al. (2019). Here, $s \geq 0$ represents the time horizon of the harvesters, or their degree of foresight, with $s=0$ corresponding to the standard 'myopic' decision-making considered in most socioeconomic-ecological models and higher values of s corresponding to longer foresight. Note that for $s \leq \tau$, decisions are still based on estimated resource states in the past/present, so that the harvesters are not so much forecasting future resource stocks as compensating for their outdated knowledge. For this reason, time horizons up to $\tau$ can be justifiable even when harvesters are assumed to be myopic, provided that they are also assumed to be aware that their knowledge of the resource is outdated.

With foresight incorporated in this way, the equation describing the harvesting effort becomes

$E_{t+1}=E_{t} e^{\eta\left[p q\left(X_{t-\tau}+s\left(X_{t-\tau}-X_{t-\tau-1}\right)-c\right)\right]}$
One point to note is the dimensionality of the system modelled here. Although we only present two equations, depending on at most 3 state variables: $E_{t}, X_{t-\tau}$, and $X_{t-\tau-1}$, in fact for delays greater than one season, we also need to store the intermediate values $X_{t-\tau+1}, \ldots, X_{t-1}$ for future use. The actual system modelled therefore has $2+\tau$ state variables. These variables do not need to be considered when interpreting the results seen here, but they do mean that more complicated dynamics may arise than would be possible for a strictly two-dimensional system.

\section{Results}

The basic model in which the time delay in the known resource level and the time horizon of the harvesters are both zerocorresponding to completely up-to-date knowledge and myopic socioeconomic decision-making - can already show cycles in some cases, but a delay in knowledge transfer can greatly increase both the likelihood and the amplitude of cycles. Our main focus is the impact of time delay and forecasting on the system, and how this depends on the rate of biomass production of the resource given by the parameter $r$. Figure 1 shows three time series of the resource-harvester system with slowly growing, long-lived resources $(r=0.1$, corresponding to a season-toseason increase in biomass of approximately $10 \%$ in the absence of harvesting and intraspecific competition). In Fig. 1a, harvesters have up-to-date knowledge, with knowledge delayed by a single season in Fig. 1b. In the first case, the oscillations are dampened and the resource levels and harvesting effort both converge to an equilibrium, leaving no danger of the resource being exhausted in the long term. The introduction of a season's delay in knowledge transfer, however, has a severe effect on the system. Even though the delay is small relative to the period of the oscillations, it causes undamped, high amplitude cycles in which the resource is left unharvested for long periods of time before being harvested close to exhaustion after it has reached a high level again. A resource dropping to such low levels is highly vulnerable to collapse through external perturbations from stochasticity or shocks, or to critical depensation.

In the case that the harvesters' knowledge of the resource level is delayed, however, the destabilising impact can be reversed by including prediction. Figure 1c shows a time series for the system with a single season's delay in knowledge, $\tau=1$, and predictions of the resource a single season ahead, $s=1$. Oscillations are restabilised by the inclusion of foresight, although the transient oscillations persist for much longer than in Fig. 1a without delay or prediction. The bifurcation portraits in Fig. 2 show how the maximum and minimum of resource values reached in the longterm dynamics depend upon the time horizon of the harvesters for various sizes of time delay. When the time delay is a single season (Fig. 2a), with myopic harvesters $(s=0)$, the resource 

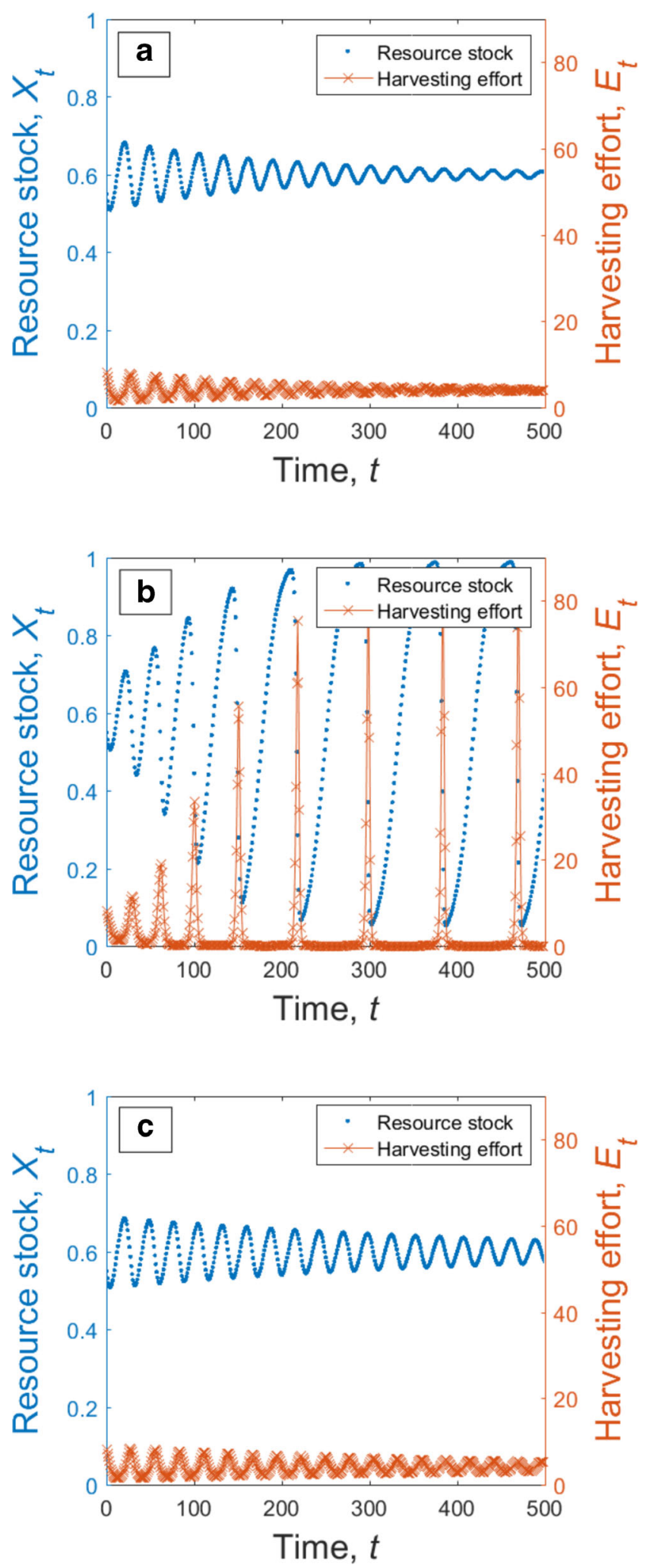

Fig. 1 Time series showing damped oscillations without delay (a), high amplitude oscillations with a delay of $\tau=1$ and without prediction (b), and damped oscillations with a delay of $\tau=1$ and prediction to a time horizon of $s=1(\mathbf{c})$. Other parameters are $r=0.1, K=1, q=0.01, \eta=$ $1.05, p=200, c=1.2$ oscillates and reaches moderately low values. Foresight on the part of the harvesters quickly stabilises the system, with a time horizon of just over one season dampening the oscillations completely to a plateau at the bioeconomic equilibrium, which is independent of the harvester foresight. However, if harvesters anticipate beyond ten seasons ahead, then oscillations reappear in the resource levels. Here, the extremely long time horizon of the harvesters causes the system to overshoot the equilibrium and causes the stabilisation mechanism to break down, although the resultant cycles have a much smaller amplitude than in the myopic case.

If the acquisition of knowledge about the resource level is delayed further, stabilisation of the oscillations through prediction on the part of the harvesters becomes more difficult. Figure $2 \mathrm{~b}$ shows how the long-term maximum and minimum of the resource level depend on the time horizon when knowledge of the resource level has a delay of three seasons. In this case, the oscillations have higher amplitude, and harvesters need to base their decisions on the expected state of the resource almost three seasons ahead to fully stabilise them. Further destabilisation of the system through overshooting also occurs for less farsighted predictions than with a smaller delay. Figure $2 \mathrm{c}$ shows that when harvesters only know the resource level from four seasons ago, no level of farsighted decisionmaking can stabilise the oscillations in the system. However, the minimum resource level reached in the cycles can be considerably higher when harvesters show foresight, whereas myopic harvesters drive the resource to low enough levels that external perturbations should eventually exhaust it. Foresight on the part of harvesters is therefore still beneficial for the persistence of the resource, even though cycles will never be stabilised completely.

Figure 3 a shows that the full dependence of the stability of the system on the knowledge delay and time horizon shows similar patterns. With long delays in the time it takes for harvesters to obtain knowledge of the resource level, high amplitude oscillations and eventual elimination of the resource are unavoidable with any amount of foresight. With a time delay of eight seasons, the resource will undergo cycles with an amplitude of at least 0.9 and so during the cycles will inevitably be reduced below $10 \%$ of its unexploited level of 1 . With a time delay of ten seasons or more, the resource will always be exhausted. The stabilising effect of prediction by the harvesters is always most effective when they show intermediate levels of foresight. For any nonzero delay in knowledge transfer, a certain farsightedness needs to be included to stabilise the system, but too much foresight will eventually destabilise the system. The range of time horizons which allow for stabilisation or at least persistence always shrinks as knowledge of the resource becomes more outdated. In the Electronic Supplementary Material, we produce similar plots with variation in the cost per unit effort $c$, the per unit resource price $p$, and the catchability coefficient $q$. In general, we see that while each of these parameters may have a stabilising or destabilising effect and therefore cause the region of stability to 
Fig. 2 Dependence of the longterm maximum and minimum resource stock values reached with respect to the time horizon, $s$, for varying information transfer delay $\tau$ in the resource-harvester system with prediction and delay. Distinct maximum and minimum curves indicate that the system shows long-term oscillations for the given time horizon. Where they coincide, this indicates that the system settles at equilibrium in the long term. Here, $c=1.5$ and $\tau=1$ (a), $\tau=3$ (b), and $\tau=4$ (c). All other parameters are kept the same as in Fig. 1
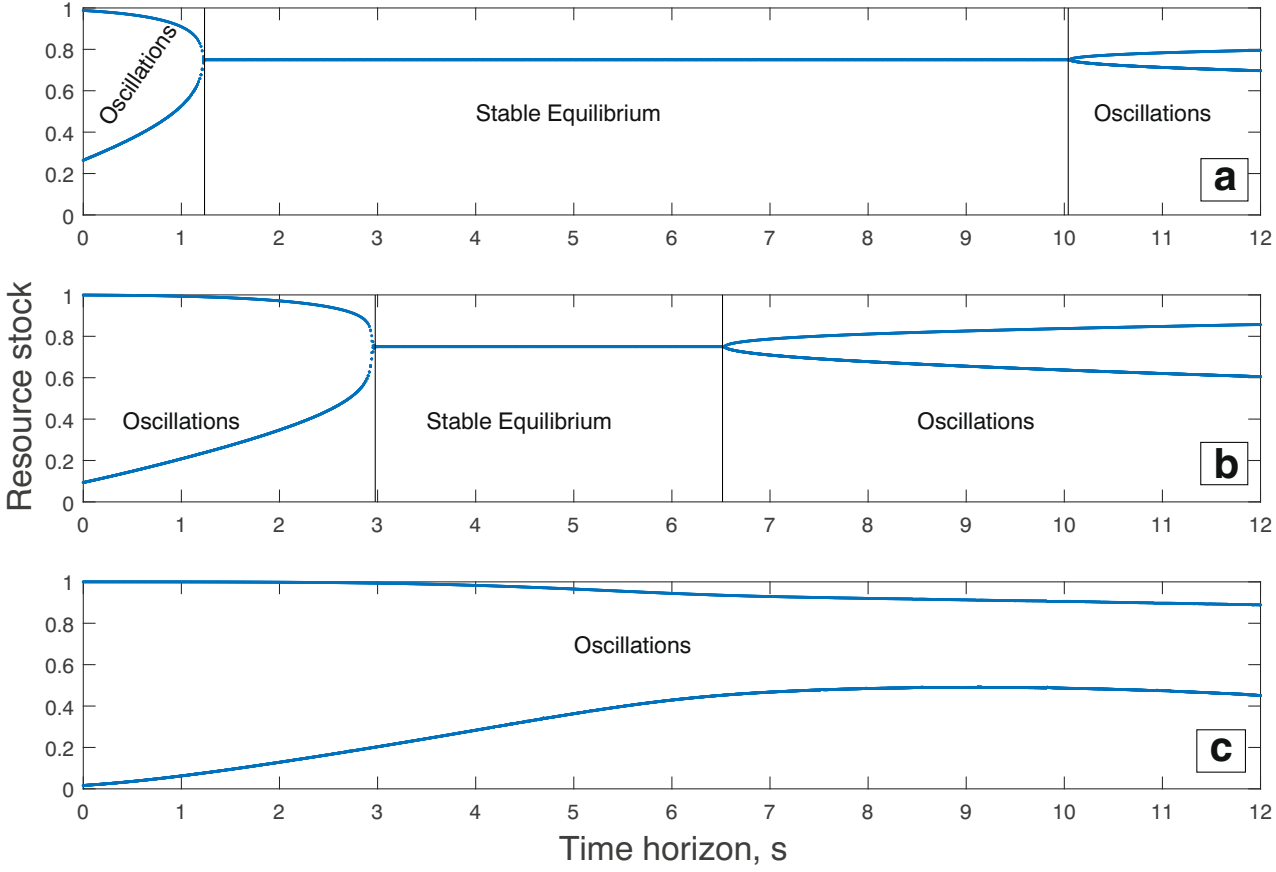

grow or shrink, the qualitative results are robust to parameter variation.

Figure $3 \mathrm{~b}$ shows the dependence of the system stability on the knowledge delay and time horizon in the case of a faster-growing resource ( $r=1$, corresponding to a season-to-season increase in biomass of approximately $170 \%$ in the absence of harvesting and intraspecific competition). We see that for faster-growing species, information delays are less destabilising to the system in the absence of harvester foresight, although for both fast- and slow-growing species a delay of five seasons is the maximum that allows the resource to persist. If foresight were not considered, this would support the conclusion that faster-growing

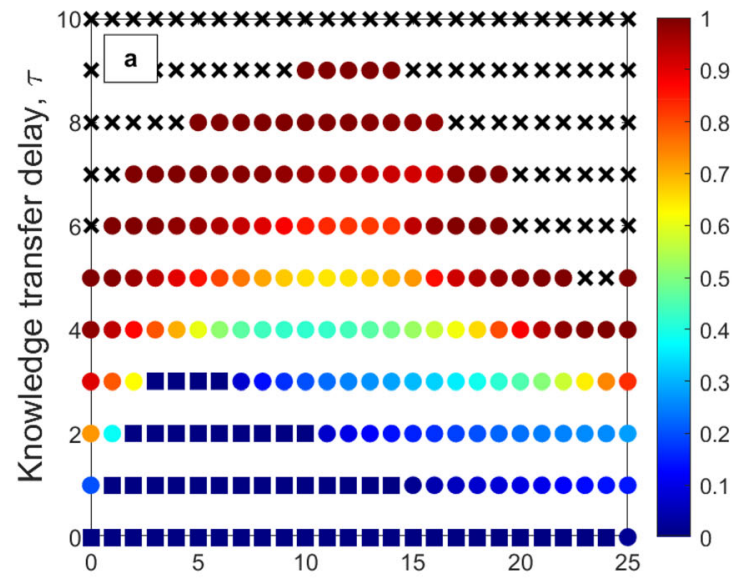

Time horizon. $\mathrm{s}$

Fig. 3 Dependence of equilibrium stability and the amplitude of undamped cycles on the time horizon $s$ and the delay in knowledge transfer $\tau$ for a slow-growing resource with basic growth parameter $r=$ 0.1 (a) and a fast-growing resource with $r=1$ (b). Squares denote a stable resources are more stable when harvested. However, we see a substantial reduction in the ability of foresight to stabilise resource-harvester cycles induced by delay, such that with knowledge of the resource stocks delayed by just two seasons, stable long-term harvesting is not possible and foresight cannot reduce the amplitude of oscillations in the resource below 0.37 (37\% of its carrying capacity). When harvesters show foresight beyond seven seasons, persistence of the resource is no longer possible. Overall, when harvesters show any level of foresight at all, delayed knowledge of the resource leads to more severe cycles and more resource exhaustion when faster-growing resources are harvested than for slower-growing resources. Long-

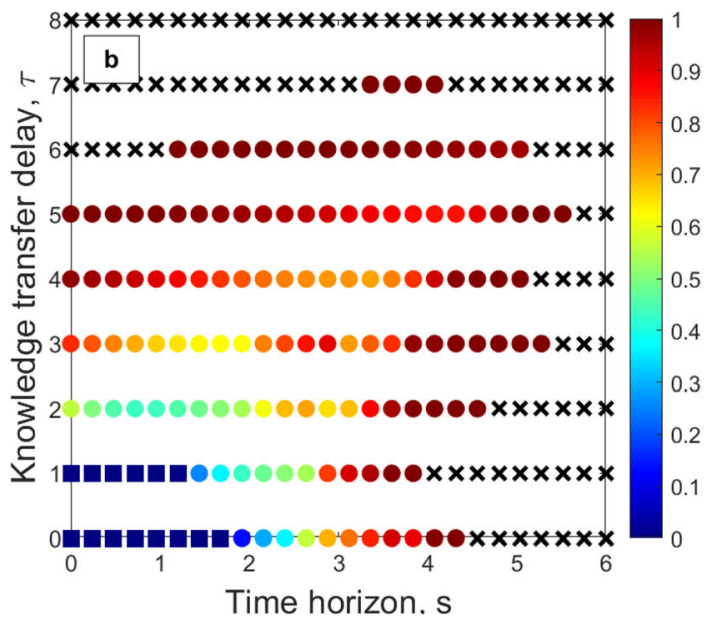

equilibrium; circles denote undamped oscillations, with the colour corresponding to the amplitude of the oscillations; black crosses denote exhaustion of the resource. All other parameters are the same as in Fig. 2 
term harvester foresight in such systems is undesirable, and foresight must broadly speaking be kept within five seasons for sustainable harvesting to be tenable. However, for large delays, moderate amounts of foresight remain desirable and even necessary for the persistence of the system.

\section{Discussion}

Socioeconomic-ecological models generally leave unchallenged the assumption that the feedback of the state of the environment is instantaneous and that human decision-making is myopic (Suzuki and Iwasa 2009; Tavoni et al. 2012; Bauch et al. 2016). The current study clearly shows that this can be misleading when it comes to questions of stability and persistence of the system. We see that when the acquisition and spread of knowledge of the resource state among the harvesters in a resourceharvester system is delayed, the socioeconomic-ecological interactions can cause the resource level and harvester effort to undergo large amplitude cycles, to the point that the resource is driven to critically low levels, after which harvesting virtually stops for long stretches of time. On the other hand, short-tomedium-term predictions of future resource stocks by the harvesters, and a consequent modification of their behaviour, can stabilise the system to bioeconomic equilibrium, provided that the delay in the knowledge of the ecosystem is not too large. The significance of these findings lie in the implication that time delays in information acquisition and application cannot reliably be ignored in social-ecological systems in which oscillations are a substantial concern and, conversely, that both the faster acquisition and application of information and appropriate forecasting of the ecological system may be overlooked solutions to instability in many social-ecological systems.

In the face of social-ecological fluctuations, especially in the harvesting of a biological resource, the research here clearly points to time delays in the ecosystem feedback as a possible cause. A model study incorporating such delays would be a sensible response, in order to check the possible impact of the development or improvement of techniques and institutions which reduce them. This may be achieved through the acquisition and speedy dissemination of information about the ecosystem state among the harvester community, rather than limiting its use to informing decision-makers. The gathering and sharing of information, however, has a cost which harvesters have little individual incentive to pay and is therefore itself a public good. Stabilisation of cycles by monitoring the resource stock would then be a second-order public good dilemma which must be resolved (Okada 2008). There may also of course be very good reasons not to share such information - alerting the harvesters of the location of protected stocks, for instance - and the benefit of such an approach requires the bio-economic equilibrium stabilised to be beneficial, which is generally not the case without some management of the resource (Clark 2010). For management, the value of ecosystem information in terms of reducing uncertainty and guiding decisions is generally appreciated - it plays a prominent role in the fisheries literature, for instance (Mäntyniemi et al. 2009; Prellezo 2017) - but the speed of acquisition and application of this information less so. With respect to Northeast Atlantic flatfish stocks, Kell et al. (2005) concluded that more accurate stock assessments may not result in better management when time lags between the collection of data and its application result in instability arising from the management procedure itself. One clear recommendation from the current study is that the collection and processing of data applied in management of biological resources should be sped up as much as possible.

The results of this paper also imply that anticipatory behaviour of humans may be worth incorporating into model studies of systems showing or vulnerable to social-ecological fluctuations. In this case, prediction may be both a cause of oscillations and a potential solution, depending on the appropriateness of the time horizon used for the timescale of the ecological dynamics: in the system considered, long-term foresight was beneficial for slowgrowing resources, whereas the inaccuracy of such long-term foresight when applied to fast-growing resources was seen to be detrimental for sustainable harvesting. One tentative conclusion to be drawn is that in the case of slowly changing environmental factors, making and disseminating medium-length forecasts (Broad et al. 2002) and promoting farsightedness among human agents (Catino 2013) can be an effective strategy for avoiding pronounced instability. The climate is one example of such a relatively slowly changing factor, and the results of Bury et al. (2019) indeed show that the maximal warming in a coupled socio-climate system was less pronounced when human decision-making was based on predicted temperature changes over longer time horizons. A stabilising effect of longer time horizons was also seen in a model of changing land use in Southern Brazil (Henderson et al. 2016), again with a relatively long ecological timescale. On the other hand, a more counterintuitive result seen in this paper is the fact that predictions too far into the future can destabilise the system (Fig. 2a, b). In particular, when the resource grows quickly (Fig. 3b), the rapid rise in the resource together with forecasting can result in the harvesting effort greatly 'overshooting' the equilibrium level and causing the resource to collapse. In this case, the accuracy of forecasting may have a greater importance than the time horizon over which it is made.

The overshooting tendency of prediction can also be seen in more slowly growing resources in the presence of significant delays (Fig. 3a). Since time delays and prediction are often simultaneously present (Kell et al. 2005), an important question concerns the length of time horizon that is most effective for stabilising a system with a given delay. Based on the current study, a general rule of thumb seems to be that time horizons should at least match the time delay in the knowledge of the resource level. When the time horizon and time delay are equal, 
decision-making is based on an estimate of the present level of the resource. Often, a time horizon significantly longer than the delay is optimal in reducing the amplitude of fluctuations, as in Figs. 3a and Figs. S1A, S2A, S2B, S3B, corresponding to forecasting of resource states at future time points. Due to the aforementioned overshooting effect, however, in fast-growing resources a time horizon roughly a season shorter than the delay gives a better stabilising effect. In this case, 'catching up to the present' is counterproductive.

Instantaneous environmental feedback and myopic human behaviour are not in themselves justifiable assumptions in virtually all human socioeconomic decision-making in an environmental context. If an environmental state is poor, awareness of this fact will still take time to filter through the community, and even once awareness is prevalent, it may not be enough to affect behavioural change (Ohe and Ikeda 2005; Lorenzoni et al. 2007). There may also be a delay while psychological barriers among individuals are overcome (Gifford 2011). On the other hand, human behaviour can also be altered by environmental concern at falling resources or rising pollution driven by predictions of the future of the environment (Hansen et al. 2004). In the case of biological resources, many are harvested on a seasonal basis, which imposes deadlines for planning/management decisions that take effect in the coming season, meaning both that data may not be applied with immediate effect and that a degree of forecasting must be made to compensate for this (Holland 2010). At the highest level of government, policy structures are also often updated on a periodic basis: China's fisheries policies, for example, are laid out on the basis of 5-year plans (Cao et al. 2017).

When modelling any system, however, simplifying assumptions need to be made in order to make the results and analysis tractable. The results seen here certainly show that there are situations where these assumptions need to be dropped, but it is useful to consider when they are valid. In our model, sufficiently large time delays are always seen to be destabilising, implying that if the lag between the acquisition of knowledge or data on the environmental state and a corresponding behavioural change is large, it cannot sensibly be ignored. Relatively modest time delays can also be destabilising when the baseline model is in parameter regimes close to destabilising bifurcations. Specifically, when effort costs are low (Fig. S1), the resource has a higher sale price (Fig. S2), or is more easily catchable (Fig. S3). In each of these cases, a delay of as little as three seasons is enough to trigger a collapse of the resource. Since forecasting is generally seen to be stabilising, assuming myopic human decision-making in models of social-ecological models with damped or undamped cycles may result in a possible stabilising mechanism being missed. In unstable social-ecological systems with shorter ecological timescales, assuming myopic human behaviour may have more serious consequences, since the inaccuracy of foresight can be a crucial destabilising mechanism.

In this paper, we have limited our study to a resourceharvester system with many simplifications and it is worth considering the impact that such simplifications could have on the conclusions. In particular, including more sophisticated representations of forecasting behaviour would help to determine whether the destabilising effect of very long foresight depends on straightforward linear prediction, or if an analogous effect is a general consequence of any form of inexact prediction. To this end, models of prediction including higherorder forecasts, longer-term memory of resource levels, or even some form of pattern recognition could be considered. It would also be more realistic to model human socioeconomic decision-making as being based upon the discounted total present value of all predicted future revenues within a given time horizon, rather than a single anticipated future profit. For the present model, we have checked that the qualitative behaviour seen here stays the same when future revenues are discounted, although stabilisation of the system through prediction becomes more difficult for the given parameters.

There are many other possible elaborations of the resourceharvester system considered here. Firstly, the role of noise in the resource dynamics or uncertainty in the harvesters' knowledge of the resource could be investigated. Uncertainty is known to be problematic for sustainable resource use (Hine and Gifford 1996; Gustafsson et al. 1999) and could result in further inaccuracies in the prediction of future resource levels and potentially prevent it from stabilising resource-harvester cycles. The assumption of a constant unit sale price in a system with large fluctuations in yield is also invalid when the particular stock of the resource modelled is significant enough that it can influence the regional or global price. When the price of a resource is dependent on its yield, following the laws of supply and demand, tipping points have been shown to arise as rare resources attain a high price and are consequently kept rare or even exhausted completely (Mansal et al. 2014; Holden and McDonald-Madden 2017), including in a resource-harvester system similar to that considered here (Fryxell et al. 2017). Finally, the interaction between delay and forecasting on the part of harvesters can be extended to models which include government-set quotas for the resource (Fryxell et al. 2010), which is a particularly interesting question considering that expectations of future government action can alter the behaviour of harvesters (Clark et al. 2005; Clark 2007).

The form of human decision-making considered here is relatively simple: harvester effort enters or exits the system based on how profitable the resource is considered to be, according to a massaction law. Many models of social-ecological systems consider the interplay of the environmental state and human socioeconomic decision-making where people have a choice to cooperate in terms of their environmental behaviour at a direct economic cost or to defect and face the indirect cost of ostracism or social pressure driven by environmental concern. This often involves general utility functions incorporating factors such as social pressure or conformism (Tavoni et al. 2012), social learning (Bury et al. 2019), and strategic interactions (Perry et al. 2018). It is certainly possible that delay and foresight may have similar destabilising and stabilising impacts as seen here in 
many systems in which socioeconomic decision-making is modelled using replicator or best-response dynamics. Indeed, as previously discussed, the work of Bury et al. (2019) hint at a stabilising role of longer time horizons in a human-climate system with social learning.

However, a stabilising response to human foresight is not guaranteed in the presence of complex strategic interactions among human actors. Indeed, prediction of a common pool resource level may exacerbate certain problems of game theory, such as the tragedy of the commons (Hardin 1968). In the absence of mechanisms promoting cooperation among users, the rational incentive of each individual user of a vulnerable resource is to intensify their exploitation of it in order to gain as much as possible before it is depleted by the others. Such a response may be triggered earlier, or even induced, by users predicting a declining resource. However, on the other hand, Jehiel (2001) and Perry et al. (2018) demonstrate a beneficial role of foresight in obtaining cooperation among competitors in repeated games and collective action problems. Overall, clarifying the combined roles of delays in ecosystem information and predictive human behaviour in more complex social-ecological systems should be a fertile ground for future research.

Acknowledgments We would like to thank John Fryxell and two anonymous reviewers for providing helpful comments and suggestions for the improvement of the article.

Author Contributions MWA conceived the study and performed the analysis. Both authors developed the model. MWA wrote the first draft, and both authors contributed to subsequent revisions.

Funding Information Open Access funding provided by Projekt DEAL.

Open Access This article is licensed under a Creative Commons Attribution 4.0 International License, which permits use, sharing, adaptation, distribution and reproduction in any medium or format, as long as you give appropriate credit to the original author(s) and the source, provide a link to the Creative Commons licence, and indicate if changes were made. The images or other third party material in this article are included in the article's Creative Commons licence, unless indicated otherwise in a credit line to the material. If material is not included in the article's Creative Commons licence and your intended use is not permitted by statutory regulation or exceeds the permitted use, you will need to obtain permission directly from the copyright holder. To view a copy of this licence, visit http://creativecommons.org/licenses/by/4.0/.

\section{References}

Barlas Y, Gunduz B (2011) Demand forecasting and sharing strategies to reduce fluctuations and the bullwhip effect in supply chains. J Oper Res Soc 62:458-473. https://doi.org/10.1057/jors.2010.188

Barraquand F, Louca S, Abbott KC, Cobbold CA, Cordoleani F, DeAngelis DL, Elderd BD, Fox JW, Greenwood P, Hilker FM et al (2017) Moving forward in circles: challenges and opportunities in modelling population cycles. Ecol Lett 20:1074-1092. https://doi. org/10.1111/ele.12789
Bauch CT, Sigdel R, Pharaon J, Anand M (2016) Early warning signals of regime shifts in coupled human-environment systems. PNAS 113:14560-14567. https://doi.org/10.1073/pnas.1604978113

Beckage B, Gross LJ, Lacasse K, Carr E, Metcalf SS, Winter JM, Howe PD, Fefferman N, Franck T, Zia A, Kinzig A, Hoffman FM (2018) Linking models of human behaviour and climate alters projected climate change. Nat Clim Chang 8:79-84. https://doi.org/10.1038/s41558-017-0031-7

Berck P, Perloff JM (1984) An open-access fishery with rational expectations. Econometrica 52:489-506. https://doi.org/10.2307/1911500

Berkes F, Colding J, Folke C (eds) (2002) Navigating social-ecological systems: building resilience for complexity and change. Cambridge University Press, Cambridge

Berryman AA (1991) Can economic forces cause ecological chaos? The case of the Northern California Dungeness crab fishery. Oikos 62: 106-109. https://doi.org/10.2307/3545457

Berryman AA, Turchin P (2001) Identifying the density-dependent structure underlying ecological time series. Oikos 92:265-270. https:// doi.org/10.1034/j.1600-0706.2001.920208.x

Bieg C, McCann KS, Fryxell JM (2017) The dynamical implications of human behaviour on a social-ecological harvesting model. Theor Ecol 10:341-354. https://doi.org/10.1007/s12080-017-0334-3

Biggs R, Carpenter SR, Brock WA (2009) Turning back from the brink: detecting an impending regime shift in time to avert it. PNAS 106: 826-831. https://doi.org/10.1073/pnas.0811729106

Bjørndal T, Conrad JM (1987) The dynamics of an open access fishery. Can J Econ 20:74-85. https://doi.org/10.2307/135232

Botsford LW, Methot RD Jr, Johnston WE (1983) Effort dynamics of the northern California Dungeness crab (Cancer magister) fishery. Can J Fish Aquat Sci 40:337-346. https://doi.org/10.1139/f83-049

Brauer F (1979) Characteristic return times for harvested population models with time lag. Math Biosci 45:295-311. https://doi.org/10. 1016/0025-5564(79)90064-6

Broad K, Pfaff ASP, Glantz MH (2002) Effective and equitable dissemination of seasonal-to-interannual climate forecasts: policy implications from the Peruvian fishery during El Niño 1997-98. Clim Chang 54:415-438. https://doi.org/10.1023/A:1016164706290

Bury TM, Bauch CT, Anand M (2019) Charting pathways to climate change mitigation in a coupled socio-climate model. PLOS Comp Biol 15:e1007000. https://doi.org/10.1371/journal.pcbi.1007000

Cao L, Chen Y, Dong S, Hanson A, Huang B, Leadbitter D, Little DC, Pikitch EK, Qiu Y, de Mitcheson YS et al (2017) Opportunity for marine fisheries reform in China. PNAS 114:435-442. https://doi. org/10.1073/pnas.1616583114

Cashin, P, Mohaddes, K, Raissi, M (2015) Fair weather or foul? The macroeconomic effects of El Niño, IMF Working Paper

Catino M (2013) Organizational myopia: problems of rationality and foresight in organizations. Cambridge University Press, Cambridge

Clark CW (2007) Rational expectations and fisheries management. In: Bjørndal T, Gordon DV, Arnason R, Sumaila UR (eds) Advances in fisheries economics. Wiley-Blackwell, Hoboken, pp 107-118

Clark CW (2010) Mathematical bioeconomics: the mathematics of conservation. Wiley, Hoboken

Clark CW, Munro GR, Sumaila UR (2005) Subsidies, buybacks, and sustainable fisheries. J Environ Econ Manag 50:47-58. https://doi. org/10.1016/j.jeem.2004.11.002

De Oliveira JAA, Kell LT, Punt AE, Roel BA, Butterworth DS (2009) Managing without best predictions: the management strategy evaluation framework. In: Payne A, Cotter J, Potter T (eds) Advances in fisheries science. Wiley, Hoboken, pp 104-134

Foster D, Young P (1990) Stochastic evolutionary game dynamics. Theor Popul Biol 38:219-232. https://doi.org/10.1016/0040-5809(90)90011-J

Fryxell JM, Packer C, McCann K, Solberg EJ, Sæther B-E (2010) Resource management cycles and the sustainability of harvested wildlife populations. Science 328:903-906. https://doi.org/10. 1126/science. 1185802 
Fryxell JM, Hilborn R, Bieg C, Turgeon K, Caskenette A, McCann KS (2017) Supply and demand drive a critical transition to dysfunctional fisheries. PNAS 114:12333-12337. https://doi.org/10.1073/pnas.1705525114

Gifford, R (2011) The dragons of inaction: Psychological barriers that limit climate change mitigation and adaptation. Am Psychol 66: 290-302. https://doi.org/10.1037/a0023566

Gourley SA (1996) Instability in a predator-prey system with delay and spatial averaging. IMA J Appl Math 56:121-132. https://doi.org/10. 1093/imamat/56.2.121

Gustafsson M, Biel A, Gärling T (1999) Overharvesting of resources of unknown size. Acta Psychol 103:47-64. https://doi.org/10.1016/ S0001-6918(99)00024-4

Haltuch MA, Brooks EN, Brodziak J, Devine JA, Johnson KF, Klibansky N, Nash RDM, Payne MR, Shertzer KW, Subbey S, Wells BK (2019) Unraveling the recruitment problem: a review of environmentally-informed forecasting and management strategy evaluation. Fish Res 217:198-216. https://doi.org/10.1016/j. fishres.2018.12.016

Hansen, JW, Marx, SM, Weber, EU (2004) The role of climate perceptions, expectations, and forecasts in farmer decision making: The Argentine pampas and South Florida: Final report of an IRI seed grant project. https://doi.org/10.7916/D8N01DC6

Hardin G (1968) The tragedy of the commons. Science 162:1243-1248. https://doi.org/10.1126/science.162.3859.1243

Hastings A (2016) Timescales and the management of ecological systems. PNAS 113:14568-14573. https://doi.org/10.1073/pnas. 1604974113

Henderson KA, Bauch CT, Anand M (2016) Alternative stable states and the sustainability of forests, grasslands, and agriculture. PNAS 113: 14552-14559. https://doi.org/10.1073/pnas.1604987113

Hine DW, Gifford R (1996) Individual restraint and group efficiency in commons dilemmas: the effects of two types of environmental uncertainty. J Appl Soc Psychol 26:993-1009. https://doi.org/10.1111/ j.1559-1816.1996.tb01121.x

Hofbauer J, Sigmund K (1998) Evolutionary games and population dynamics. Cambridge University Press, Cambridge

Holden MH, McDonald-Madden E (2017) High prices for rare species can drive large populations extinct: the anthropogenic Allee effect revisited. J Theor Biol 429:170-180. https://doi.org/10.1016/j.jtbi.2017.06.019

Holland DS (2010) "Management strategy evaluation and management procedures: Tools for rebuilding and sustaining fisheries.", OECD Food, agriculture and fisheries working papers, No. 25, OECD Publishing. https://doi.org/10.1787/5kmd77jhvkjf-en

Hutchinson, GE (1948) Circular causal systems in ecology. Ann NY Acad Sci 50:221-246. https://doi.org/10.1111/j.1749-6632.1948.tb39854.x

Jankovic M, Petrovskii S (2014) Are time delays always destabilizing? Revisiting the role of time delays and the Allee effect. Theor Ecol 7: 335-349. https://doi.org/10.1007/s12080-014-0222-z

Jehiel P (2001) Limited foresight may force cooperation. Rev Econ Stud 68:369-391. https://doi.org/10.1111/1467-937X.00173

Kell LT, Pastoors MA, Scott RD, Smith MT, Van Beek FA, O'Brien CM, Pilling GM (2005) Evaluation of multiple management objectives for Northeast Atlantic flatfish stocks: sustainability vs. stability of yield. ICES J Mar Sci 62:1104-1117. https://doi.org/10.1016/j.icesjms.2005.05.005

King JR, McFarlane GA, Punt AE (2015) Shifts in fisheries management: adapting to regime shifts. Philos Trans R Soc B 370:20130277. https://doi.org/10.1098/rstb.2013.0277

Lande R, Engen S, Saether B-E (2003) Stochastic population dynamics in ecology and conservation. Oxford University Press, Oxford

Lewison RL, Crowder LB, Read AJ, Freeman SA (2004) Understanding impacts of fisheries bycatch on marine megafauna. Trends Ecol Evol 19:598-604. https://doi.org/10.1016/j.tree.2004.09.004

Lorenzoni I, Nicholson-Cole S, Whitmarsh L (2007) Barriers perceived to engaging with climate change among the UK public and their policy implications. Glob Environ Chang 17:445-459. https://doi. org/10.1016/j.gloenvcha.2007.01.004
Mansal F, Nguyen-Huu T, Auger P, Balde M (2014) A mathematical model of a fishery with variable market price: sustainable fishery/ over-exploitation. Acta Biotheor 62:305-323. https://doi.org/10. 1007/s10441-014-9227-7

Mäntyniemi S, Kuikka S, Rahikainen M, Kell LT, Kaitala V (2009) The value of information in fisheries management: North Sea herring as an example. ICES J Mar Sci 66:2278-2283. https://doi.org/10.1093/ icesjms/fsp206

Maxwell JC (1868) I. On governors. Proc R Soc Lond 16:270-283. https://doi.org/10.1098/rspl.1867.0055

May RM (1973) Time-delay versus stability in population models with two and three trophic levels. Ecology 54:315-325. https://doi.org/ $10.2307 / 1934339$

Niculescu S-I (2001) Delay effects on stability: a robust control approach. Springer, London

Ohe M, Ikeda S (2005) Global warming: risk perception and riskmitigating behavior in Japan. Mitig Adapt Strateg Glob Chang 10: 221-236. https://doi.org/10.1007/s1 1027-005-6138-6

Okada A (2008) The second-order dilemma of public goods and capital accumulation. Public Choice 135:165-182. https://doi.org/10.1007/ s11127-007-9252-z

Ostrom E (1990) Governing the commons. Cambridge University Press, Cambridge

Ostrom E (2009) A general framework for analyzing sustainability of social-ecological systems. Science 325:419-422. https://doi.org/ $10.1126 /$ science. 1172133

Perry L, Shrestha MD, Vose MD, Gavrilets S (2018) Collective action problem in heterogeneous groups with punishment and foresight. J Stat Phys 172:293-312. https://doi.org/10.1007/s10955-018-2012-2

Pinsky ML, Jensen OP, Ricard D, Palumbi SR (2011) Unexpected patterns of fisheries collapse in the world's oceans. PNAS 108:83178322. https://doi.org/10.1073/pnas.1015313108

Prellezo R (2017) Expected economic value of the information provided by fishery research surveys. Fish Res 190:95-102. https://doi.org/ 10.1016/j.fishres.2017.02.004

Richard J-P (2003) Time-delay systems: an overview of some recent advances and open problems. Automatica 39:1667-1694. https:// doi.org/10.1016/S0005-1098(03)00167-5

Ricker WE (1954) Stock and recruitment. J Fish Res Board Can 11:559623. https://doi.org/10.1139/f54-039

Shelton AO, Mangel M (2011) Fluctuations of fish populations and the magnifying effects of fishing. PNAS 108:7075-7080. https://doi. org/10.1073/pnas. 1100334108

Smith VL (1969) On models of commercial fishing. J Polit Econ 77:181198. https://doi.org/10.1086/259507

Steele DH, Andersen R, Green JM (1992) The managed commercial annihilation of northern cod. Newfoundland Labrador Stud 8:34-68

Suzuki Y, Iwasa Y (2009) The coupled dynamics of human socio-economic choice and lake water system: the interaction of two sources of nonlinearity. Ecol Res 24:479-489. https://doi.org/10.1007/s11284-008-0548-3

Tavoni A, Schlüter M, Levin S (2012) The survival of the conformist: social pressure and renewable resource management. J Theor Biol 299:152-161. https://doi.org/10.1016/j.jtbi.2011.07.003

Taylor PD, Jonker LB (1978) Evolutionary stable strategies and game dynamics. Math Biosci 40:145-156. https://doi.org/10.1016/00255564(78)90077-9

Worm B, Hilborn R, Baum JK, Branch TA, Collie JS, Costello C, Fogarty MJ, Fulton EA, Hutchings JA, Jennings S, Jensen OP, Lotze HK, Mace PM, McClanahan TR, Minto C, Palumbi SR, Parma AM, Ricard D, Rosenberg AA, Watson R, Zeller D (2009) Rebuilding global fisheries. Science 325:578-585. https://doi.org/10.1126/science.1173146

Xia J, Liu Z, Yuan R, Ruan S (2009) The effects of harvesting and time delay on predator-prey systems with Holling type II functional response. SIAM J Appl Math 70:1178-1200. https://doi.org/10.1137/ 080728512 